\title{
THE EFFECTS OF HATCHING DATE AND PARENTAL QUALITY ON CHICK GROWTH AND CRECHING AGE IN THE CHINSTRAP PENGUIN (PYGOSCELIS ANTARCTICA):
} A FIELD EXPERIMENT

\author{
JuAN MORENo, ${ }^{1,3}$ ANDRÉs BARbosa, ${ }^{1}$ JAIME PotTI, ${ }^{2}$ AND \\ SANTIAGo MERINO2 \\ ${ }^{1}$ Museo Nacional de Ciencias Naturales-CSIC, J. Gutierrez Abascal 2, E-28006 Madrid, Spain; and \\ ${ }^{2}$ Departamento de Biología Animal, Universidad de Alcalá de Henares, \\ E-28871 Alcalá de Henares, Spain
}

\begin{abstract}
Negative effects of late breeding on chick growth and creching and fledging ages of chicks have been reported for Chinstrap Penguins (Pygoscelis antarctica). In a Chinstrap Penguin rookery on Deception Island, we experimentally tested two hypotheses to explain these effects of hatching date: (1) late breeding pairs are formed by low-quality breeders that are not able to feed their chicks efficiently and are forced to leave them unguarded at younger ages; and (2) late breeding pairs experience a conflict between properly caring for their chicks and commencing the period of premolt reserve storage. By exchanging chicks among nests hatched six days apart, we separated the effects of quality of adults (as expressed by their breeding dates) from the hatching date of chicks. We measured bill and flipper length and weighed chicks at 17 and 44 days of age, and noted the age at which chicks were left unguarded by parents. Late-hatched chicks attained smaller sizes and masses and were left unguarded at earlier ages than early-hatched chicks independent of the breeding date of the adults raising them. Also, chicks hatched on the same date but raised by adults with different breeding dates reached the same sizes and masses and were left unguarded at similar ages. Thus, seasonal changes in chick growth and creching age are related to hatching date, not to differences in parental quality. Received 26 April 1996, accepted 8 August 1996.
\end{abstract}

IN TEMPERATE AREAS, several components of fitness are increased by early breeding (Nilsson 1994). Offspring survival usually declines with date of hatching (Daan et al. 1988, Price et al. 1988, Perrins and McCleery 1989, Hochachka 1990, Tinbergen and Daan 1990). This trend is not restricted to passerines, because evidence of a seasonal decline in offspring survival exists for raptors (Newton and Marquiss 1984, Daan et al. 1990, Steeger and Ydenberg 1993) and seabirds (Perrins 1966, Parsons et al. 1976, Hedgren 1981, Wanless and Harris 1988). Also, the survival of parents may increase with early breeding, because more time will be available for molting and for improving body condition before the onset of winter (Brömssen and Jansson 1980). The seasonal decline in breeding success may be related to differences in parental quality of early and late breeders (Price et al. 1988), or to differences in the environment experienced by early and late breeders (Verhulst and Tinbergen 1991). Understanding the causal

\footnotetext{
${ }^{3}$ E-mail: monjm19@pinar1.csic.es
}

links between timing of breeding and reproductive success is crucial for understanding the fitness consequences of competing reproductive decisions (Daan et al. 1990, Tinbergen and Daan 1990). Experimental evidence for temperate passerines points to a direct causal link between hatching date and breeding success independent of the breeding date of parents (Verhulst and Tinbergen 1991, Norris 1993).

Negative effects of late breeding on breeding success have been reported in Adélie Penguins (Pygoscelis adeliae; Taylor 1962, Spurr 1975; but see Davis and McCaffrey 1986) and Gentoo Penguins ( $P$. papua; Bost and Jouventin 1991; but see Williams 1990). In the course of a long-term study of the Chinstrap Penguin (P. antarctica) on Deception Island (Viñuela et al. 1996), we have shown that late hatching leads to depressed growth and earlier creching and fledging (departure for the sea). These trends may be due to poorer reproductive performance of late breeders, which may be young, inexperienced, or otherwise "low-quality" individuals that are constrained to lay after the optimal period (Ainley 1975, Ainley et al. 1983; but see 
Williams 1990). If breeding date expresses some inherent property of pairs that is not dependent solely on age, then it should be consistent among years. This was shown for Chinstrap Penguins by the significant repeatability of hatching dates from year to year (Viñuela et al. 1996). Lowquality parents would feed their chicks less efficiently and would have to leave them unguarded earlier to improve their feeding capacity (i.e. two parents at sea simultaneously instead of one). Earlier fledging would be another consequence of poor feeding performance by late parents. A seasonal decrease in food availability could also be involved in a reduction in breeding performance with breeding date. In that case, we should expect a decline in breeding success to be manifested during the last part of the chick-raising period for the latest breeders in the population.

An alternative possibility is that the seasonal decline in breeding performance results from a conflict in late-breeding individuals between feeding chicks and feeding themselves in order to store reserves for postnuptial molt. Pygoscelid penguins breeding in Antarctica have to compress a complete breeding cycle into the short antarctic summer. Selection for early breeding should be very strong, balanced, of course, by selection for avoidance of adverse climatic conditions in spring. Any delay in the commencement of breeding may retard the onset of postbreeding molt, with possible negative repercussions on adult survival. The intense molt of penguins requires fasting on land during periods ranging from 13 to 34 days, depending on species (Adams and Brown 1990). The energy reserves used to sustain this period of fasting are accumulated during prolonged premolt periods during which foraging effort may be higher than that of adults attending chicks (Adams and Brown 1990). Given that thermal insulation is impaired during molt (Adams and Brown 1990), molting before the onset of autumn probably is advantageous. That there is a premium on molting early is also indicated by the observation that failed breeders begin molting before the fledging of young in the colonies (Moreno pers. obs.). Given that penguins are long-lived and have multiple opportunities to breed (Williams 1994), late breeders must face conflicting pressures between feeding chicks and advancing the period of premolt reserve storage (Viñuela et al. 1996). This conflict should result in depressed chick growth and reduced fitness for late-hatched chicks.
The advancement of creching with increasing hatching date in Adélie (Taylor 1962) and Chinstrap penguins (Viñuela et al. 1996) could reflect a parental tradeoff between present reproduction and future survival prospects. Creching is defined by the abandonment of chicks by guarding parents. It occurs when the parent with guarding duties leaves the chicks at the nest and departs for the sea. Guarding is not resumed by the other parent when it returns from the sea, and chicks have to join other chicks to avoid harassment by conspecific adults and attacks by Brown Skuas (Catharacta lonnbergi; Young 1994). Early creching has costs for chicks in terms of harassment by adults (Penney 1968, Young 1994, Moreno pers. obs.), increased risk of predation (Davis 1982, Young 1994, Moreno pers. obs.), and increased energy expenditure due to feeding chases (Bustamante et al. 1982). The return to creches after feeding chases is especially critical for chicks (Young 1994, Moreno pers. obs.). Although creches protect chicks from predation and harassment, this protection is markedly lower than that offered by a guarding adult (Young 1994, Moreno pers. obs.). Also, chicks left unguarded at younger ages grow less well despite the fact that simultaneous foraging bouts by the two parents are initiated earlier (Viñuela et al. 1996). This effect is independent of hatching date (Viñuela et al. 1996). Thus, all available evidence supports the notion that early creching reduces offspring fitness. The fact that chicks left alone earlier are not favored by the increased foraging capacity of their parents suggests that parents are the recipients of the potential benefits. The cessation of guarding allows parents to increase the frequency and duration of foraging bouts, which allows parents to retain a greater share of captured food (Culik 1994). Our estimates of daily predation risk from leopard seals (Hydrurga leptonyx; $0.2 \%$ of adults leaving or returning to the rookery may be taken each day at the end of the breeding season) appear too small to offset the advantage of improved condition through more frequent foraging bouts. Also, if predation risk was crucial, we would expect a strong selective pressure favoring prolonged guarding shifts and spacedout feeding visits, which is not the case in this species (Moreno unpubl. data). The earlier fledging of late-hatched chicks (Viñuela et al. 1996) would be another consequence of the increasing parental reluctance to continue investing in the present brood at the cost of delaying storage of premolt reserves. 
By exchanging chicks hatched six days apart, we experimentally tested the two most plausible hypotheses proposed to explain the effects of hatching date: (1) late breeding pairs are formed by low-quality breeders that are not able to properly feed their chicks and are forced to leave them on their own at earlier ages; and (2) late breeding pairs experience a conflict between properly caring for their chicks and commencing the period of premolt reserve storage, given the need to molt before a certain date. The second hypothesis does not negate the fact that pairs may be of different quality, but that these differences determine the seasonal decline in offspring fitness as expressed by growth and creching age. In fact, it actually assumes that hatching date should be related to some measure of parental quality, otherwise there would be no variation in hatching date given the selective pressures favoring early breeding. However, whereas the first hypothesis considers that parental quality constrains the posthatching reproductive performance of breeding pairs, the second hypothesis explains the seasonal decline in offspring fitness as the result of a shift in the tradeoff between present and future reproductive potential of the parents.

\section{METHODS}

The study was conducted in the Vapour Col Chinstrap Penguin rookery on Deception Island, South Shetlands $\left(63^{\circ} 00^{\prime} \mathrm{S}, 60^{\circ} 40^{\prime} \mathrm{W}\right)$ during the austral summer of 1994-95. In three large colonies (discrete nest aggregations) of more than 500 nests, we marked with numbered sticks 80 early (hatched 22 to 23 December) and 80 late nests (hatched 28 to 29 December), where both eggs hatched (clutch size two at each nest). The mean and median hatching dates in an independent sample of randomly selected nests in the rookery were 26 and 25 December, respectively (range 19 December to 6 January; $n=148$ ). One day after hatching of the late nests, we exchanged the recently hatched chicks in 25 nests with the 6-day-old chicks of 25 nests in the early group. These chicks became the "early parents/late chicks group" and "late parents/early chicks group," respectively. In 30 early and 30 late nests, we exchanged broods between nests with the same hatching date one day after hatching so that no parents raised their own broods. These nests controlled for the possible effects of the chick exchange itself, and will be called "early control group" and "late control group." Finally, 25 early and 25 late nests were not manipulated and left as pure controls, called the "early" and "late" nests. By performing the exchanges before chicks were one week old, we avoided the problem of parental recognition of their own chicks, because it has been shown repeatedly that adult-offspring recognition in penguins does not develop until chicks attain the age of 17 days (Davis and McCaffrey 1989, Seddon and van Heezik 1993). Nests occupied peripheral and central positions (less than or beyond two nests from the edge). The distributions of nest positions in the different experimental treatments did not differ $\left(\chi^{2}=5.44, \mathrm{df}=5, P=0.36\right)$. Most breeding adults were banded with metal flipper bands (standard $34 \times 17 \mathrm{~mm}$ penguin bands produced by Lambournes Ltd., Solihull, England).

At 17 days of age chicks were weighed with a spring balance and measured (flipper length with a ruler, bill length with a dial caliper). On periodic visits after that age (daily whenever possible), we recorded if chicks were accompanied by a guarding parent or if they had been left alone. The difference between the first date on which chicks were seen without their parent and hatching date is termed the "creching age" of the family. Before the formation of creches, chicks were banded with numbered metal flipper bands. All banded chicks were weighed and measured again at the age of 43 to 44 days. Some chicks could not be properly identified at 17 days of age due to chick aggregation, but were later banded and could thus be measured at 44 days.

Mortality of chicks due to parental desertion, starvation, or predation by Brown Skuas (Moreno et al. 1994) was recorded on each visit. We searched the surroundings of study colonies carefully for dead chicks. According to our experience, skuas consume chicks of creching age close to the natal colonies and always leave skeletons and flippers untouched. In a previous study, we showed that our visits to nests had no significant effect on chick survival (Moreno et al. 1994). Two nests were lost from the study sample before the first measurement and one between the first and second measurements due to disappearance of nest markers before the chicks could be banded. Measurements and masses of chicks were averaged per brood. Chick survival was square-root transformed for parametric analyses. We used ANOVA after checking for normality and homoscedasticity of the data (Sokal and Rohlf 1981). Creching age was not normally distributed (Kolmogorov-Smirnov test, $P<0.0001$ ) and was analyzed with a Kruskal-Wallis test and the corresponding multiple range test (Siegel and Castellan 1988).

\section{RESUlts}

No significant differences existed between the early control and early groups in chick masses and measurements at the ages of 17 and 44 days (Table 1). Nor were there any significant differences between the late control and late groups (Table 1). Thus, chick exchanges had no detectable effect on chick growth. We therefore pooled the early control and early groups on 
TAble 1. Measurements $(\bar{x} \pm \mathrm{SE}[n])$ of Chinstrap Penguin chicks in exchange control treatments (exchanged chicks have same hatching date) and pure controls at 17 and 44 days of age. Early and late chicks differ in age by six days. All comparisons (i.e. "early control" vs. "early" and "late control" vs. "late") were not significant ( $t$-tests, $P>0.05)$.

\begin{tabular}{llccc}
\hline \hline & Early control & Early & Late control & Late \\
\hline \multicolumn{7}{c}{17 days } \\
Bill length (mm) & $23.14 \pm 0.28(24)$ & $23.14 \pm 0.24(27)$ & $21.37 \pm 0.26(22)$ & $22.07 \pm 0.29(26)$ \\
Flipper length (mm) & $116.8 \pm 1.6(24)$ & $116.0 \pm 1.4(27)$ & $118.3 \pm 2.1(22)$ & $123.5 \pm 1.7(26)$ \\
Body mass (g) & $1,118 \pm 24(24)$ & $1,101 \pm 19(27)$ & $1,093 \pm 30(22)$ & $1,145 \pm 23(26)$ \\
\multicolumn{7}{c}{44 days } \\
Bill length (mm) & $38.49 \pm 0.39(22)$ & $37.73 \pm 0.33(29)$ & $36.69 \pm 0.35(20)$ & $37.20 \pm 0.36(26)$ \\
Flipper length (mm) & $194.2 \pm 1.4(22)$ & $194.0 \pm 1.1(29)$ & $190.2 \pm 1.5(21)$ & $190.6 \pm 0.9(26)$ \\
Body mass (g) & $3,304 \pm 55(22)$ & $3,257 \pm 48(29)$ & $3,006 \pm 49(21)$ & $3,063 \pm 60(26)$ \\
\hline
\end{tabular}

the one hand, and the late control and late groups on the other hand, for analyses of chick growth. They will be called "early control" and "late control" hereafter. Creching ages differed significantly between the late control and late groups (Mann-Whitney $U$-test, $P=0.004$ ), so the pure control and manipulation control treatments were not pooled in the analysis of creching age.

We performed two-way ANOVAs with parental breeding date (expressed by hatching date of their brood) and brood hatching date as factors for the different chick measurements and masses at 17 and 44 days of age (Table 2). At 17 days, parental breeding date had no significant effect on any measurement or on mass, whereas brood hatching date had a significant effect on bill length (Table 2). Late-hatched chicks (experimental and control) had significantly shorter bills than early-hatched chicks at 17 days (Fig. 1). There were no significant interactions between factors at this stage (Table 2). At 44 days, brood hatching date had highly significant effects on chick measurements and mass, whereas parental breeding date had no significant effects; there also was a significant interaction term for bill length (Table 2). This term was due to the overlap in bill measurements between the late control broods and the late parents/early chicks broods (Fig. 2). In general, the late-hatched chicks were smaller and lighter than the early-hatched chicks, without regard to the breeding date of the parents caring for them (Fig. 2).

Creching age differed between experimental treatments $(H=82.67, \mathrm{df}=5, P<0.001)$. Earlyhatched chicks were left on their own significantly later than were late-hatched chicks, independent of experimental treatment, whereas there were no differences between groups of chicks hatched on the same date (Fig. 3).

Chick survival was similar in all treatments, both from 0 to 17 days $(F=0.88, \mathrm{df}=5$ and $152, P=0.49)$ and from 17 to 44 days $(F=0.42$, $\mathrm{df}=5$ and $140, P=0.82$; Table 3 ). Chick survival was lower during the first than during the second period $\left(89.2 \%\right.$ vs. $94.0 \% ; \chi^{2}=4.28, \mathrm{df}=1$, $P=0.03)$. No banded chicks in the study sample

TABLE 2. Results of two-way ANOVA with parental breeding date (expressed by hatching date of their own brood) and brood hatching date as factors on measurements of Chinstrap Penguin chicks at 17 and 44 days of age.

\begin{tabular}{|c|c|c|c|c|c|c|c|c|c|}
\hline & \multicolumn{3}{|c|}{ Parental breeding date } & \multicolumn{3}{|c|}{ Brood hatching date } & \multicolumn{3}{|c|}{ Interaction } \\
\hline & $F$ & $\mathrm{df}$ & $P$ & $F$ & $\mathrm{df}$ & $P$ & $F$ & $\mathrm{df}$ & $P$ \\
\hline \multicolumn{10}{|c|}{17 days } \\
\hline Bill length & 0.04 & 1,144 & 0.84 & 29.58 & 1,144 & $<0.0001$ & 0.69 & 1,144 & 0.41 \\
\hline Flipper length & 0.47 & 1,144 & 0.49 & 2.84 & 1,144 & 0.09 & 3.81 & 1,144 & 0.053 \\
\hline Body mass & 1.88 & 1,144 & 0.17 & 3.66 & 1,144 & 0.57 & 0.76 & 1,144 & 0.39 \\
\hline \multicolumn{10}{|c|}{44 days } \\
\hline Bill length & 0.68 & 1,141 & 0.42 & 18.07 & 1,141 & $<0.0001$ & 5.29 & 1,141 & 0.02 \\
\hline Flipper length & 0.02 & 1,142 & 0.90 & 11.31 & 1,142 & 0.001 & 2.60 & 1,142 & 0.10 \\
\hline Body mass & 2.38 & 1,142 & 0.12 & 40.52 & 1,142 & $<0.0001$ & 0.39 & 1,142 & 0.53 \\
\hline
\end{tabular}



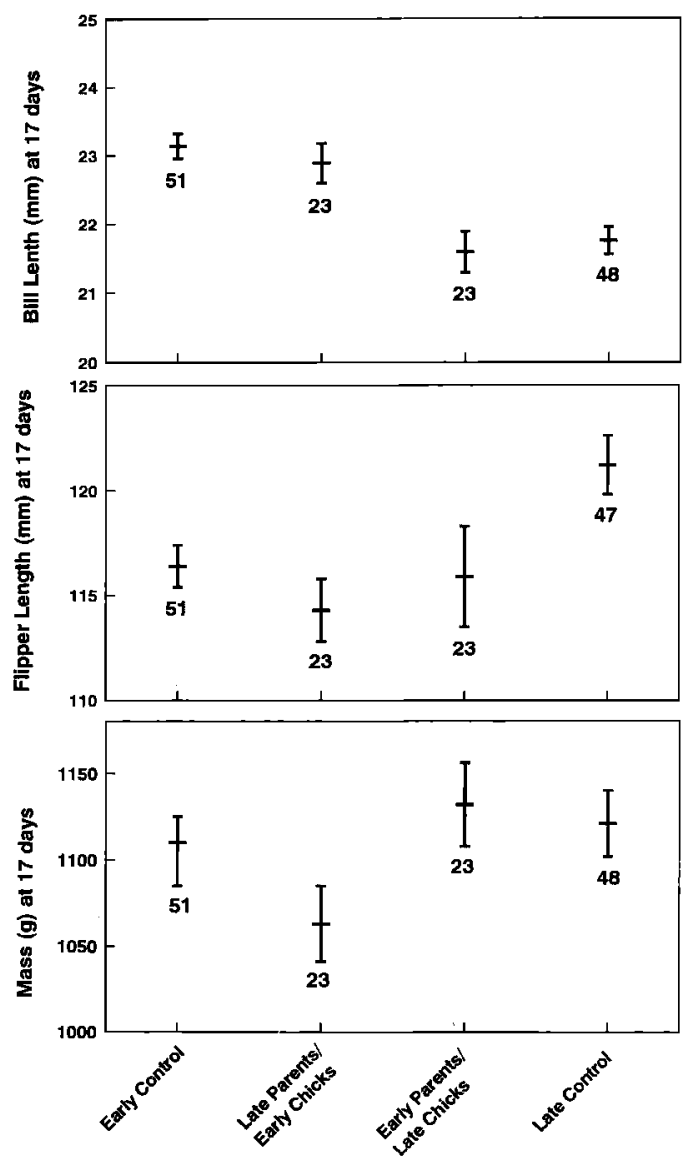

Fig. 1. Differences among experimental treatments in bill length (upper), flipper length (middle), and body mass (lower) of Chinstrap Penguin chicks at 17 days of age. Values are $\bar{x} \pm \mathrm{SE}$ (sample size below error bars).

older than 44 days were found dead, so chick survival until $\mathbf{4 4}$ days is a suitable measure of fledging success.

\section{Discussion}

A seasonal decline in breeding success is almost ubiquitous in birds breeding in non-tropical areas (Daan et al. 1988). Seasonal variation in reproductive success can be attributed to seasonal trends in food abundance in the environment (Lack 1966), or to individuals of lower reproductive capability nesting later than more capable individuals (Price et al. 1988). The first possibility does not explain trends in several populations breeding in temperate areas because food resources frequently are increasing

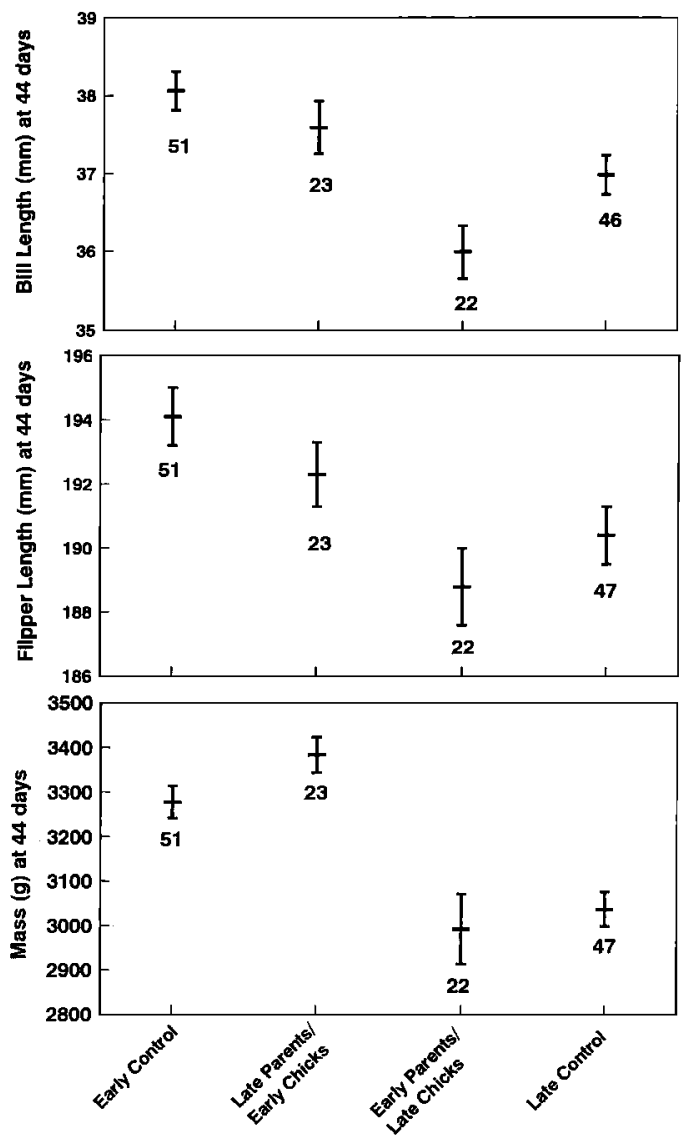

Fig. 2. Differences among experimental treatments in bill length (upper), flipper length (middle), and body mass (lower) of Chinstrap Penguin chicks at 44 days of age. Values are $\bar{x} \pm \mathrm{SE}$ (sample size below error bars).

while breeding success declines (Daan et al. 1988). The best way to unravel whether environmental changes or individual variation determines the seasonal trend in reproductive success is through experimental manipulations. This has been achieved either by forcing females to renest (Parsons 1975, Verhulst and Tinbergen 1991) or by exchanging broods between pairs of different breeding dates (Norris 1993). Experimental evidence for temperate passerines points to a direct causal link between hatching date and offspring survival independent of the quality of parents (Verhulst and Tinbergen 1991, Norris 1993).

The seasonal trend in breeding success may affect prefledging (Parsons 1975, Newton and Marquiss 1984, Wanless and Harris 1988) or postfledging survival of offspring (Perrins and 


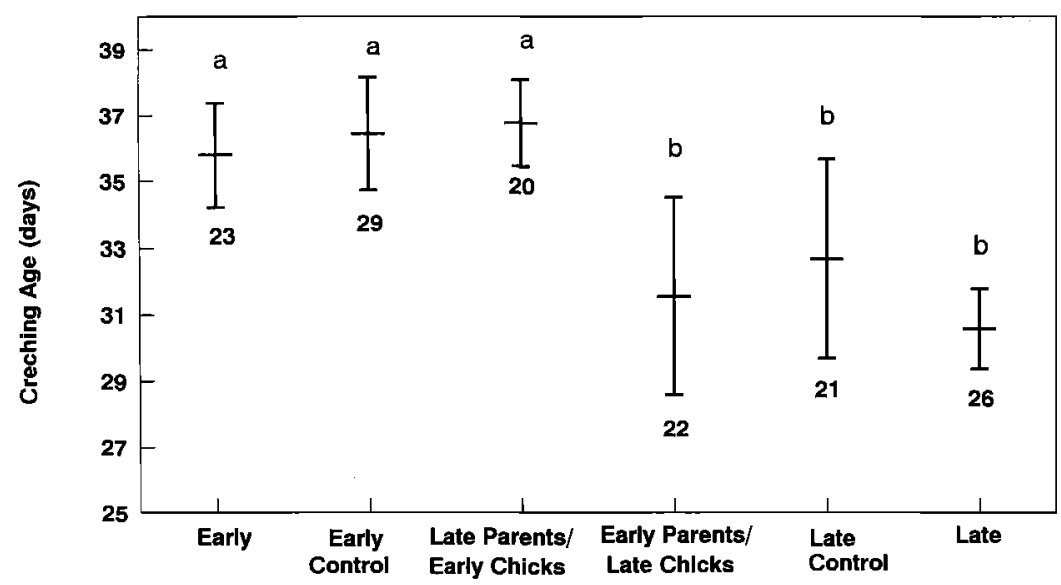

Fig. 3. Creching ages $(\bar{x} \pm S E$, sample size below error bars) of Chinstrap Penguin broods in different experimental treatments. Values with the same letter are statistically equal (multiple range test associated with Kruskal-Wallis test).

McCleery 1989, Hochachka 1990). A reduction in offspring fitness in the nest with the advance of the season may be linked to decreased chances of recruitment of late-hatched young (Daan et al. 1990, Tinbergen and Daan 1990). Parents may be less committed to care for offspring of reduced reproductive value, given that parental effort entails costs in terms of future reproductive prospects (Lessells 1991, Stearns 1992). Thus, late-breeding parents may either be constrained in their performance by their lower capabilities, or voluntarily restricting their effort in favor of the present brood in order to increase their chances for future reproduction. The second option appears especially relevant for long-lived birds. If late breeders are constrained, their performance should not increase if breeding is experimentally advanced. The opposite would be true for early breeders. However, if performance depends on a life-history-based tradeoff between present and future reproduction, then late breeders would increase their effort when caring for early-hatched young, and the opposite would be true for early breeders.

We have performed a chick exchange experiment in the Chinstrap Penguin to separate parental quality and seasonal effects. In this species, we found a seasonal decline in offspring mass and an earlier creching age for late-hatched chicks (Viñuela et al. 1996). That a seasonal decline in food availability alone could explain the seasonal trends in growth and creching age appears implausible, because the chick-raising periods of early and late pairs in our experiment overlapped considerably (breeding dates were just six days apart). If a general decline in food availability was operating, it should have occurred after the early chicks reached 46 days and in a period of six days. The study sample included only nests hatching around the mean and median hatching dates in the population, to avoid including especially late breeders and

TABLE 3. Survival of Chinstrap Penguin chicks from hatching to 17 days and from 17 to 44 days for the different experimental treatments. Each brood started with two chicks and broods sometimes lost one or both chicks.

\begin{tabular}{lccccc}
\hline \hline \multicolumn{1}{c}{ Treatment } & Initial no. & No. chicks at No. chicks at Survival from & Survival from \\
of chicks & 17 days & 44 days & 0 to 17 days & \begin{tabular}{c} 
17 to 4 days \\
\hline Early
\end{tabular} \\
Early control & 60 & 57 & 53 & 0.950 & 0.929 \\
Late parents/early chicks & 48 & 44 & 41 & 0.916 & 0.930 \\
Early parents/late chicks & 50 & 47 & 45 & 0.940 & 0.957 \\
Late control & 50 & 44 & 41 & 0.880 & 0.930 \\
Late & 50 & 42 & 39 & 0.840 & 0.928 \\
\hline
\end{tabular}


to reduce the risk of including environmental effects at the end of the breeding season. Our test is conservative with respect to the effects of hatching date on breeding performance, because we have not included in our sample the earliest and latest nests.

If parental quality explains the trends in growth and creching ages observed, then chicks raised by early parents should grow better and have later creching ages than chicks raised by late parents without regard to their own hatching date. If parents are restricting their effort due to a shift in the tradeoff between present and future reproduction, then early-hatched chicks would grow better and be left unguarded at later ages independent of the quality of the parents as expressed by their own breeding dates. The results of our experiment clearly show that the hatching dates of chicks affect the behavior of the adults raising them as expressed by growth and creching age, and that there are no significant differences in any measurements or in creching ages between chicks hatched on the same date but raised by parents with breeding dates differing by six days. Thus, early breeders are not willing to invest as much effort in late chicks as in early chicks, and late breeders are willing to work harder for early than for late chicks. Decreased growth and early creching of late-hatched chicks are not determined by parental quality but by an independent seasonal factor. The seasonal trends that we found may be the consequence of a restriction of breeding time in Antarctica. After fledging of their chicks, adult penguins must molt, and they must do it before the arrival of autumn storms. There is probably a premium on initiating premolt reserve storage as soon as possible. Premolt reserve storage involves long periods at sea and very high foraging intensities (Adams and Brown 1990). After a critical time (perhaps indicated by changes in daylength), adults may reduce investment in the current brood to divert resources to premolt reserve storage, thus favoring their own survival (Bost and Jouventin 1991). This must be especially important for Chinstrap Penguins, because among pygoscelids they have the latest laying dates in Antarctica (Trivelpiece et al. 1987).

The restriction in parental effort for late breeders is predicted by life-history theory, because late-hatched chicks may have a reduced reproductive value as found in many other temperate species (Daan et al. 1988, Clutton-Brock
1991). The difference in creching ages between experimental treatments suggests a gradual decline in the parental disposition to invest in their chicks, which probably results from a shift in the life-history tradeoffs determining parental investment. Future reproduction will become progressively more important in relation to present reproduction during the course of the breeding season in long-lived birds such as penguins.

\section{ACKNOWLEDGMENTS}

Our study was supported by grant ANT94-0036 from the Spanish C.I.C.Y.T. (Plan Nacional Antártico). Transport to and from Deception Island was made on the "Hespérides," Spanish Navy. We gratefully acknowledge the hospitality and logistic support offered at the Spanish Base "Gabriel de Castilla" of the Spanish Army. H. Roldán, J. Ibáñez, and J. L. Ruano kindly assisted us in field work. The comments by $P$. Bednekoff and two anonymous reviewers were extremely helpful in improving an earlier version of the manuscript.

\section{LITERATURe CiTED}

ADAMS, N. J., AND C. R. BRowN. 1990. Energetics of molt in penguins. Pages 297-315 in Penguin biology (L. S. Davis and J. T. Darby, Eds.). Academic Press, San Diego, California.

AINLEY, D. G. 1975. Development of reproductive maturity in Adélie Penguins. Pages 139-157 in The biology of penguins (B. Stonehouse, Ed.). Macmillan, London.

AINLEY, D. G., R. E. LeRESCHE, AND W. J. L. SLAden. 1983. Breeding biology of the Adélie Penguin. University of California Press, Berkeley.

Bost, C. A., AND P. JouventiN. 1991. The breeding performance of the Gentoo Penguin Pygoscelis papua at the northern edge of its range. Ibis 133: 14-25.

BRÖMSSEN, A. VON, AND C. JANSSON. 1980. Effects of food addition to Willow Tit Parus montanus and Crested Tit $P$. cristatus at the time of breeding. Ornis Scandinavica 11:173-178.

Bustamante, J., J. J. Cuervo, and J. Moreno. 1982. The function of feeding chases in the Chinstrap Penguin Pygoscelis antarctica. Animal Behaviour 44:753-759.

Clutton-Brock, T. H. 1991. The evolution of parental care. Princeton University Press, Princeton, New Jersey.

Culik, B. 1994. Energetic costs of raising Pygoscelid penguin chicks. Polar Biology 14:205-210.

DAan, S., C. Dijkstra, R. H. DRent, AND T. MEIJer. 1988. Food supply and the annual timing of avian reproduction. Pages 392-407 in Acta XIX Con- 
gressus Internationalis Ornithologici (H. Ouellet, Ed.). Ottawa, Ontario, 1986. National Museum of Natural Sciences, Ottawa.

DAAN, S., C. Dijkstra, AND J. M. Tinbergen. 1990. Family planning in the Kestrel (Falco tinnunculus): The ultimate control of covariation of laying date and clutch size. Behaviour 114:83-116.

DAvis, L.S. 1982. Creching behaviour of Adélie Penguin chicks. New Zealand Journal of Zoology 9:279-286.

DAvis, L. S., AND F. T. MCCAFfrey. 1986. Survival analysis of eggs and chicks of Adélie Penguins (Pygoscelis adeliae). Auk 103:379-388.

DAVIS, L. S., AND F. T. MCCAFFREY. 1989. Recognition and parental investment in Adélie Penguins. Emu 89:155-158.

HEDGREN, S. 1981. Effects of fledging weight and time of fledging on survival of Guillemot Uria aalge chicks. Ornis Scandinavica 12:51-54.

HochACHKA, W. 1990. Seasonal decline in reproductive performance of Song Sparrows. Ecology 71:1279-1288.

LACK, D. 1966. Population studies of birds. Oxford University Press, Oxford.

LESSELLS, C. M. 1991. The evolution of life histories. Pages 32-68 in Behavioural ecology, an evolutionary approach (J. R. Krebs and N. B. Davies, Eds.). Blackwell Scientific Publications, Oxford.

Moreno, J., L. M. Carrascal, J. J. SANZ, J. A. Amat, AND J. J. Cuervo. 1994. Hatching asynchrony, sibling hierarchies and brood reduction in the Chinstrap Penguin Pygoscelis antarctica. Polar Biology 14:21-30.

NEWTON, I., AND M. MARQuiss. 1984. Seasonal trends in the breeding performance of Sparrowhawks. Journal of Animal Ecology 53:809-829.

NiLsson, J. A. 1994. Energetic bottle-necks during breeding and the reproductive cost of being too early. Journal of Animal Ecology 63:200-208.

NoRRIs, K. 1993. Seasonal variation in the reproductive success of Blue Tits: An experimental study. Journal of Animal Ecology 62:287-294.

PARsons, J. 1975. Seasonal variation in the breeding success of the Herring Gull: An experimental approach to pre-fledging success. Journal of Animal Ecology 44:553-573

Parsons, J., G. Chabryzk, AND N. Duncan. 1976. Effects of hatching date on post-fledging survival in Herring Gulls. Journal of Animal Ecology 45: 667-675.

PenNey, R. L. 1968. Territorial and social behaviour in the Adélie Penguin. Antarctic Research Series 12:83-131.

Perrins, C. M. 1966. Survival of young Manx Shearwaters in relation to their presumed date of hatching. Ibis 108:132-135.

Perrins, C. M., AND R. MCCleery. 1989. Laying dates and clutch size in the Great Tit. Wilson Bulletin 101:236-253.

Price, T., M. KIRKPATRICK, AND S. ARNOLD. 1988. Directional selection and the evolution of breeding date in birds. Science 240:798-799.

Seddon, P. J., AND Y. VAN HefzIK. 1993. Parentoffspring recognition in the Jackass Penguin. Journal of Field Ornithology 64:27-31.

SieGEl, S., AND N. J. Castellan. 1988. Nonparametric statistics for the behavioral sciences. McGrawHill, New York.

SOKAL, R. R., AND F. J. Rohlf. 1981. Biometry, 2nd ed. W. H. Freeman, San Francisco.

SPURR, E. B. 1975. Breeding of the Adélie Penguin Pygoscelis adeliae at Cape Bird. Ibis 117:324-338.

STEARNS, S. C. 1992. The evolution of life histories. Oxford University Press, Oxford.

STEEGER, C., AND R. C. YDENberg. 1993. Clutch size and initiation date of Ospreys: Natural patterns and the effect of a natural delay. Canadian Journal of Zoology 71:2141-2146.

TaYlor, R. H. 1962. The Adélie Penguin Pygoscelis adeliae at Cape Royds. Ibis 104:176-204.

TINBERGEN, J. M., AND S. DAAN. 1990. Family planning in the Great Tit (Parus major): Optimal clutch size as integration of parent and offspring fitness. Behaviour 114:161-190.

TRIVELPIECE, W. Z., S. G. TRIVELPIECE, AND N. J. VOLKMAN. 1987. Ecological segregation of Adélie, Gentoo and Chinstrap penguins at King George Island, Antarctica. Ecology 68:351-361.

Verhulst, S., AND J. M. TINBERGEN. 1991. Experimental evidence for a causal relationship between timing and success of reproduction in the Great Tit Parus m. major. Journal of Animal Ecology 60:269-282.

Viñuela, J., J. Moreno, L. M. Carrascal, J. J. Sanz, J. A. AMAT, M. Ferrer, J. Belliure, AND J. J. Cuervo. 1996. The effect of hatching date on parental care, chick growth and chick mortality in the Chinstrap Penguin Pygoscelis antarctica. Journal of $\mathrm{Zo}$ ology (London) 240:51-58.

Wanless, S., AND M. P. HaRRIS. 1988. The importance of relative laying date on breeding success of the Guillemot Uria aalge. Ornis Scandinavica 19:205-211.

Williams, T. D. 1990. Annual variation in breeding biology of Gentoo Penguins Pygoscelis papua at Bird Island, South Georgia. Journal of Zoology (London) 222:247-258.

WIlliams, T. D. 1994. The penguins. Oxford University Press, Oxford.

Young, E. 1994. Skua and penguin. Cambridge University Press, Cambridge.

Associate Editor: J. Ekman 